\title{
Extraction of polysaccharides from Amaranthus hybridus L. by hot water and analysis of their antioxidant activity
}

\author{
Yujia Tang ${ }^{\text {Equal first author, } 1}{ }^{1}$, Yirong Xiao ${ }^{\text {Equal first author, } 2}{ }^{2}$ Zizhong Tang ${ }^{\text {Corresp., }}{ }^{1}$, Weiqiong Jin ${ }^{1}$, Yinsheng Wang ${ }^{1}$, Hui Chen ${ }^{1}$, \\ Huipeng Yao ${ }^{1}$, Zhi Shan ${ }^{1}$, Tongliang Bu ${ }^{1}$, Xiaoli Wang ${ }^{1}$ \\ ${ }^{1}$ College of Life Sciences, Sichuan Agricultural University, Ya'an, China \\ 2 Sichuan Agricultural University Hospital, Ya'an, China \\ Corresponding Author: Zizhong Tang \\ Email address: 14126@sicau.edu.cn
}

Background. Amaranthus hybridus L. is an annual herb that belongs to the Amaranthceae family, a type of multi-purpose grain, vegetable and feed crop that has received considerable attention due to its great economic value. However, the composition of polysaccharides from $A$. hybridus has rarely been previously reported. Methods. In this study, the aboveground part of $A$. hybridus was used as material and polysaccharides were isolated by the hot water extraction method. Two acidic polysaccharides were isolated and purified by Sevage method and DEAE cellulose-32 column chromatography. Results. Two acidic polysaccharides were obtained from $A$. hybridus: AHP-H-1 and AHP-H-2. There were significant differences between the monosaccharide content from each sample according to GC-MS. AHP-H-2 had higher antioxidant activity in vitro than AHP-H-1. The DPPH radical scavenging rate of $2 \mathrm{mg} / \mathrm{mL}$ AHP-H-2 was $80 \%$, its hydroxyl radical scavenging rate was approximately $48.5 \%$, its superoxide anion radical scavenging rate was $85.3 \%$ and its reduction ability of $\mathrm{Fe}^{3+}$ was approximately 0.92 . The total antioxidant capacity of each milligram of AHP-H-2 was 6.5, which was higher than ascorbic acid. Conclusion. The results of this study promote the effective use of $A$. hybridus and provide a theoretical basis for its development. 


\section{Extraction of polysaccharides from Amaranthus hybridus L. by hot 2 water and analysis of their antioxidant activity}

3 Yujia Tang ${ }^{1 \dagger}$, Yirong Xiao ${ }^{2 \dagger}$, Zizhong Tang ${ }^{1 *}$, Weiqiong Jin ${ }^{1}$, Yinsheng Wang ${ }^{1}$, Hui Chen ${ }^{1}$,

4 Huipeng $\mathrm{Yao}^{1}$, Zhi Shan ${ }^{1}$, Tongliang Bu${ }^{1}$, Xiaoli Wang ${ }^{1}$

5 1. College of Life Sciences, Sichuan Agricultural University, Ya'an 625014, China

6 2. Sichuan Agricultural University Hospital, Ya’an 625014, China

$7 \quad *$ Corresponding author:

8 Zizhong Tang, Tel: +86 0835 2886126; Fax: +86 0835 2886136; E-mail: 14126@sicau.edu.cn

$9 \dagger$ These authors contributed equally to this work and should be considered co-first authors.

\section{ABSTRACT}

Background. Amaranthus hybridus L. is an annual herb that belongs to the Amaranthceae family, a type of multi-purpose grain, vegetable and feed crop that has received considerable attention due to its great economic value. However, the composition of polysaccharides from $A$. hybridus has rarely been previously reported. Methods. In this study, the aboveground part of $A$. hybridus was used as material and polysaccharides were isolated by the hot water extraction method. Two acidic polysaccharides were isolated and purified by Sevage method and DEAE

17 cellulose-32 column chromatography. Results. Two acidic polysaccharides were obtained from A. hybridus: AHP-H-1 and AHP-H-2. There were significant differences between the monosaccharide content from each sample according to GC-MS. AHP-H-2 had higher 
antioxidant activity in vitro than AHP-H-1. The DPPH radical scavenging rate of $2 \mathrm{mg} / \mathrm{mL}$ AHP-

21 H-2 was $80 \%$, its hydroxyl radical scavenging rate was approximately $48.5 \%$, its superoxide

22 anion radical scavenging rate was $85.3 \%$ and its reduction ability of $\mathrm{Fe}^{3+}$ was approximately 0.92 .

23 The total antioxidant capacity of each milligram of AHP-H-2 was 6.5, which was higher than

24 ascorbic acid.

25 Conclusion. The results of this study promote the effective use of $A$. hybridus and provide a theoretical basis for its development.

\section{INTRODUCTION}

Amaranthus hybridus L., an annual herb that belongs to the Amaranthus family Amaranthceae, is a type of common grain amaranth crop (Sun, 1998; Zhu, 1990). According to "The Shen Nong Ben Cao Jing" (Gu, 2004) records, A. hybridus has many effects, such as improving eyesight, relaxing the bowels, dispelling cold, removing heat, etc. Amaranth, containing fiber, protein, tocols, squalene, and the substances possessing cholesterol-lowering function, is a particularly important crop for developing countries (Johns and Eyzaguirre, 2007). Most recently, a comprehensive review was published, which is focusing mainly on health effects, such as hypocholesterolemic activity, influence on the immune system, antitumor effect, action on blood glucose levels, effects on liver functions, hypertension, antienemic effect, antioxidant activity,

37 celiac disease, and antiallergic action (Caselato-Sousa and Amaya-Farf'an, 2012). The carbohydrate content among the various components of the grain is the highest and can reach up 
39

40

41

42

to $60 \%$.

Previous studies have suggested that plant polysaccharides have a wide range of biological activities, such as antioxidant (Yang et al., 2014; Tahmouzi et al., 2014; Han et al., 2015) antitumour, immunoregulation (Kim et al., 1990), hypoglycaemic, and hyperlipidemic (Jin et al., 2013; Chen et al., 2013; Tang et al., 2013; Zhou et al., 2016; Liu et al., 2002; Liao et al., 2016) and so on. Polysaccharides usually form conjugates with proteins, polyphenols and lipids. It has been reported that the protein components in polysaccharides have an effect on the free radical scavenging activity of some parts of the polysaccharides. The free radical scavenging activities of exopolysaccharides studied in the literature were significantly correlated with protein content. Phenolic compounds, especially phenolic acids, play an important role in free radical scavenging of xylan and xylo-oligosaccharides. Therefore, the degree of complexation of polysaccharides with total phenols or proteins may indicate their strong antioxidant capacity. The phenolic and protein contents of pectin and other complex carbohydrates on the market were analyzed. It was found that the phenolic content of LPS, pectin and polygalacturonic acid was higher, the protein content of xylan and pectin was higher, and their carbohydrate content was basically higher. The experimental results showed that pectin and polygalacturonic acid had stronger antioxidant ability and antioxidant ability. The chemical ability may be attributed to phenols and proteins (Hu, 2016). Research into the grain amaranth is now mainly focused its exploitation as a forage crop and use in healthcare, but polysaccharides from amaranth have been rarely reported. $A$. hybridus is a widely-distributed, resource-abundant low-cost plant (Li, 2009), with high content 
59 of soluble polysaccharide plant. It is distributed in southern Shaanxi, Sichuan, Guizhou in China,

60 and also found to be located in Europe, North America and South America. Comparison with

61 some polysaccharides extracted from all kinds of plants, such as Actinidia arguta Planch,

62 Actinidia kolomikta Planch and Bamboo indicated that A. hybridus has relatively high

63 polysaccharide content. However, the research of the polysaccharides in A. hybridus is limited,

64 as a result, the resources lag behind in the research and development of phytochemistry.

65 Therefore, A. hybridus was used as material, and the hot water method was applied to extract

66 polysaccharides. Then, analyses of the purification, physicochemical properties and biological

67 activity were carried out, and the results of this study promote the effective utilization of $A$.

68 hybridus and provide a theoretical basis for the extraction process and product development of

69 polysaccharides from $A$. hybridus.

MATERIALS AND METHODS

71

\subsection{Materials}

A. hybridus was obtained from Sichuan Agricultural University and identified by Professor Hui Chen. The materials were placed in the shade to dry and stored at room temperature. In this study, the shoots of $A$. hybridus was used as material. The mature stage of $A$. hybridus was used for experimentation. The plants were cultivated on the farm of Sichuan Agricultural University. They were sown in April and harvested in September. Nitro blue tetrazolium (NBT), KBr (spectroscopically pure) and a dextran standard were purchased from Sigma (St. Louis, MO, 
78 USA). 2,2-diphenyl-1-picrylhydrazyl (DPPH) was purchased from Yuanye Co. (Shanghai,

79 China), Ascorbic acid(Vc) was purchased from Sinopharm Chemical Reagent Co. (China),

80 DEAE cellulose-32 was purchased from Whatman Co. (Maidstone, Kent, UK), Sephadex G-100

81 was purchased from Pharmacia Co. (New York, NY, USA). All other chemicals and reagents

82 were analytical grade.

83 2.2 Sample handling and calculation

84

85

86

87

88

89

90

91

92

93

94

95

96

\subsubsection{Sample preparation}

The aboveground parts of $A$. hybridus were collected and washed, dried and passed through 80 mesh screens. Samples were crushed by a grinder. For defatting and removing pigment, the powder was placed in a Soxhlet extractor and added to refluxing preheated mineral ether $\left(60^{\circ} \mathrm{C}\right.$ $90^{\circ} \mathrm{C}$ ) at a temperature of $70^{\circ} \mathrm{C}$ until the mineral ether was colourless. A step-wise extraction, using solvents having increasing polarity, was used to eliminate pigments, phenolics, carotenoids, and other interfering compounds from the plant materials used for polysaccharide preparation. Dry the extracted powder and place it in a drying bottle for backup.

2.2.2 Preparation of crude polysaccharides

$20 \mathrm{~g}$ of the prepared powder of $A$. hybridus in the drying bottle was weighed and mixed with an appropriate volume of distilled water according to the desired solid-liquid ratio. The filtrate was dissolved by hot water extraction and concentrated; then, the resulting solution was mixed with four times its volume of anhydrous ethanol for precipitation for $24 \mathrm{~h}$ at $4^{\circ} \mathrm{C}$. The extraction 
97 solutions were separated by centrifugation $(5000 \times \mathrm{g}$ for $15 \mathrm{~min})$. Then, the crude polysaccharides

98 were air-dried and weighed. The yield (\%) of the polysaccharides was calculated as follows:

99 Extraction yield $(\%)=\frac{m_{1}}{m_{2}} \times 100$

100 where $\mathrm{m}_{1}(\mathrm{~g})$ is the dried crude polysaccharide weight; $\mathrm{m}_{2}(\mathrm{~g})$ is the powder weight of $A$. hybridus.

1012.3 Purification of crude polysaccharides

102 2.3.1 Protein removal from the crude polysaccharides and purification

103 After precipitation of the polysaccharide powder with ethanol, crude polysaccharides were 104 deproteinated using the Sevage method following Zhang (2007). Sevage (chloroform:N-butanol $105=4: 1)$ was added to the polysaccharide solution using a separating funnel to remove proteins. 106 The upper liquid was concentrated using a rotary evaporator(RB-52AA vacuum rotary 107 evaporator); then, the concentrated solution was precipitated by the addition of a 4-fold volume 108 of anhydrous ethanol and freeze-drying. The resulting polysaccharide was prepared in a solution 109 at $10 \mathrm{mg} / \mathrm{mL}$ and applied to a DEAE-32 column (Li, 2006). The polysaccharide was eluted 110 stepwise with distilled water and $0.1-1 \mathrm{~mol} / \mathrm{L} \mathrm{NaCl}$ at $0.6 \mathrm{~mL} / \mathrm{min}$. The fractions containing 111 sugar were collected at 10 min per tube using an automatic collector(automatic partial collector

112 BS160A), and the total sugar content was determined and shown in an elution curve.

\section{$113 \quad 2.3 .2$ Assessment of molecular weight}

114 The average molecular weight of the polysaccharide was determined by gel column 
115 chromatography equipped with Sephadex G-100. The column was calibrated with T-series 116 dextran $(\mathrm{T}-7,10,40,50,500)$ as the standard, and the molecular weights of the polysaccharides 117 were estimated by reference to the elution standard curve.

$118 \quad$ 2.3.3 Component analysis

119 The neutral saccharide content of the crude polysaccharides was determined based on the 120 phenol-sulfuric acid method (Cuesta et al., 2003; Albalasmeh et al., 2013). The protein content 121 was determined by the Bradford method (Yang \& Wu 1998) using bovine serum albumin (BSA) 122 as a reference. The uronic acid content was determined based on the sulfuric acid-carbazole 123 method (Fang et al., 2011). Polysaccharide component analysis of A. hybridus was adopted by derivatization gas chromatography, and gas chromatography-mass spectrometer (GC-MS). 10 $\mathrm{mg}$ of the polysaccharide sample was weighed, then $2 \mathrm{~mol} / \mathrm{L} 5 \mathrm{~mL}$ trifluoroacetic acid (TFA) was added and sealed. Place the ampoule bottle in shaker to dissolve the polysaccharide. After the polysaccharide was dissolved, the solution was hydrolyzed $8 \mathrm{~h}$ at $100^{\circ} \mathrm{C}$ to dissolve it fully. Then, the ampoule bottle was opened, steamed water fully and dissolved in $3 \mathrm{~mL} \mathrm{ddH}_{2} \mathrm{O}$. Reduction of $4 \mathrm{~h}$ by adding $20 \mathrm{mg} \mathrm{NaBH} 4$ at room temperature, neutralization reaction of acetic acid, excess sodium borohydride and drying. Then $1 \mathrm{~mL}$ acetic anhydride and $1 \mathrm{~mL}$ pyridine was added. After shaking and dissolving, acetylation was carried out at $100^{\circ} \mathrm{C}$. After the reaction

132 lasted for $6 \mathrm{~h}$, acetic anhydride and pyridine were dried. The remaining powder was dissolved in $133 \mathrm{CHCl}_{3}$ and analyzed by GC-MS. Weighing standard sample of monosaccharides mannose, 134 rhamnose, galactose, lyxose, xylose, fructose and glucose, derivatization of saccharonitrile 
135 acetate and GC-MS analysis were carried out according to the above methods. An RTX5mx

136 capillary column was used with a flow speed of $1.9 \mathrm{~mL} / \mathrm{min}$ and sample size of $1 \mu \mathrm{L}$. The initial

137 column temperature was $40^{\circ} \mathrm{C}$ and was increased to $290^{\circ} \mathrm{C}$ at a rate of $6^{\circ} \mathrm{C}$ per minute after 2

$138 \mathrm{~min}$. The temperature was maintained for $10 \mathrm{~min}$, and the temperature of the detector was

139 maintained at $290^{\circ} \mathrm{C}$.

140 2.3.4 Ultraviolet (UV) and infrared (IR) analysis

141 The crude polysaccharide of $A$. hybridus was dissolved and diluted in an aqueous solution and

142 scanned from 200 to $800 \mathrm{~nm}$ with a UV spectrophotometer. Then, 1-2 $\mathrm{mg}$ of sample was crushed

143 and pressed into $1 \mathrm{~mm}$ pellets for FT-IR measurement. For investigating the functional group,

144 the crude polysaccharide was analysed with a FT-IR spectrophotometer (FTIR-8400S, Shimadzu

145 Co., Japan) over a frequency range of 4000-400 $\mathrm{cm}^{-1}$.

146 2.3.5 Scanning electron microscope (SEM)

147 The scanning electron microscope (SEM) was used with the ion sputtering deposition method.

148 The polysaccharide powder was subjected to electric conduction and placed in a JSM-7500 SEM

149 platform. The accelerated voltage was $15.0 \mathrm{kV}$ and was increased by 1000 and 3000 times. 
153 determined by the DPPH method (Zhang et al., 2015). Briefly, $2 \mathrm{~mL}$ of DPPH solution was

154 mixed with a gradient sample solution at different concentrations $(0-2 \mathrm{mg} / \mathrm{mL})$ in tubes. The

155 mixture was placed in the dark for $30 \mathrm{~min}$ at room temperature. The absorbance was measured at

$156517 \mathrm{~nm}$. Distilled water was used as the control group, and Vc was used as the positive control.

157 The DPPH radical scavenging ability was calculated with the following equation:

158 DPPH scavenging effect $(\%)=\left(1-\frac{A_{1}-A_{2}}{A_{0}}\right) \times 100$

159 where $\mathrm{A}_{0}$ is the absorbance of DPPH without sample, $\mathrm{A}_{1}$ is the absorbance of sample and DPPH, 160 and $\mathrm{A}_{2}$ is the absorbance of sample without DPPH. solution $0.5 \mathrm{~mL}$, PBS $1.0 \mathrm{~mL}$ and sample solution $0.5 \mathrm{~mL}$; then, $\mathrm{FeSO}_{4} 0.5 \mathrm{~mL}$ and $\mathrm{H}_{2} \mathrm{O}_{2} 0.5 \mathrm{~mL}$ were added. The reaction mixture was incubated in a water bath at $37^{\circ} \mathrm{C}$ for $30 \mathrm{~min}$. Absorbance was measured at $510 \mathrm{~nm}$ after the mixture was cooled to room temperature. Vc was used as the positive control. The hydroxyl radical scavenging ability was calculated with the following equation: 
171 Scavenging rate $(\%)=\left(1-\frac{\mathrm{A}_{1}-\mathrm{A}_{2}}{\mathrm{~A}_{0}}\right) \times 100$

172 where $A_{0}$ is the absorbance of the sample after reaction with hydroxyl radicals, $A_{1}$ is the

173 absorbance of the sample, and $\mathrm{A}_{2}$ is the absorbance without $\mathrm{H}_{2} \mathrm{O}_{2}$.

174 2.4.3 Superoxide anion free radical scavenging assay

175 The superoxide anion radical scavenging capacity was determined using the method of 176 Beauchamp and Jia et al. (Beauchamp \& Fridovich, 1971; Jia et al., 1999). The solution was 177 prepared as follows: $\mathrm{PBS}(\mathrm{pH}=7.4,0.05 \mathrm{~mol} / \mathrm{L})$, riboflavin $\left(3.3 \times 10^{-6} \mathrm{~mol} / \mathrm{L}\right)$, methionine $(0.01$ $178 \mathrm{~mol} / \mathrm{L})$, NBT $\left(4.6 \times 10^{-5} \mathrm{~mol} / \mathrm{L}\right)$, and crude polysaccharide solution of sample $(0-2 \mathrm{mg} / \mathrm{mL})$. The 179 reaction system contained the four solutions mentioned above and the sample solution $1.0 \mathrm{~mL}$, 180 and distilled water was used in the control group. Absorbance was measured at $560 \mathrm{~nm}$ after 181 incubating for $30 \mathrm{~min}$. The superoxide anion radical scavenging ability was calculated with the 182 following equation:

183 Scavenging rate $(\%)=\left(1-\frac{\mathrm{A}_{1}-\mathrm{A}_{2}}{\mathrm{~A}_{0}}\right) \times 100$ where $A_{0}$ is the absorbance of sample; $A_{1}$ is the absorbance of the sample after the reaction.

$185 \quad 2.4 .4 \mathrm{Fe}^{3+}$ reducing capacity assay

187 blue method (Hu, 2010; Sun, 2010). Vitamin C was used as the positive control. The solution 188 was prepared as follows: Vc gradient solution $(0-2 \mathrm{mg} / \mathrm{mL})$, sample gradient solution $(0-2$ 
189

190

191

192

193

$\mathrm{mg} / \mathrm{mL}), \operatorname{PBS}(\mathrm{pH}=6.6,0.2 \mathrm{~mol} / \mathrm{L})$, potassium ferricyanide $(1 \%, \mathrm{w} / \mathrm{v})$, trichloroacetic acid (TCA, $10 \%$, w/v), and $\mathrm{FeCl}_{3}(0.1 \%$, w/v). Then, $2.5 \mathrm{~mL}$ of the sample solution, $2.5 \mathrm{~mL}$ of PBS; and 1.0 $\mathrm{mL}$ of potassium ferricyanide were added to the EP tubes. The reaction mixture was incubated in a water bath at $50^{\circ} \mathrm{C}$ for $20 \mathrm{~min}$. When the tubes had cooled to room temperature, w $2.5 \mathrm{~mL}$ of TCA was added and the samples were centrifuged this mixture at $3000 \mathrm{rpm}$ for $10 \mathrm{~min} .2 .0 \mathrm{~mL}$ of the supernatant was added into $2.0 \mathrm{~mL}$ of distilled water or $0.5 \mathrm{~mL}$ of $\mathrm{FeCl}_{3}$. Absorbance was measured at $700 \mathrm{~nm}$ after incubation for $10 \mathrm{~min}$. Absorbance was defined as the reducing power.

\subsubsection{Total antioxidant capacity assay}

The measurement of total antioxidant activity is able to illustrate the antioxidant capacity when the sample acts on the body. The T-AOC Kit was used in this study. One unit of total antioxidant capacity was defined as when the absorbance of the reaction system was increased by 0.01 per milligram (Sun, 2013).

\section{RESULTS}

\subsection{Hot water extraction of polysaccharide assay analysis}

Response surface methodology was used to optimize polysaccharides from $A$. hybridus, and the optimal conditions were as follows: exaction temperature, $92^{\circ} \mathrm{C}$; extraction time, $214 \mathrm{~min}$; and ratio of water to raw material, $43 \mathrm{~mL} / \mathrm{g}$. The maximum extraction percent of polysaccharide was $8.29 \% \pm 0.15 \%$. Response surface methodology(RSM) is an optimization method. It takes the response of the system (such as extraction rate in extraction chemistry) as a function of one 
208

209

210

211

212

213

214

215

216

21

218

219

220

221

222

223

224

225

226

or more factors (such as extractant concentration, acidity, etc.). The graph technology is used to show the relationship of the functions, therefore, the optimal conditions would be determined.

The chemical components of the crude polysaccharide sample are shown in Table 1. The polysaccharide content was $39.4 \%$, uronic acid content was $28.13 \pm 0.35 \%$ and protein content was $3.14 \pm 0.25 \%$.

3.2 FT-IR spectroscopy analysis of crude polysaccharide

The FT-IR spectroscopy results of AHP-H is shown in Fig. 1. The spectra showed a broad stretching vibration peak at $3417 \mathrm{~cm}^{-1}$ for the O-H group and a narrow and weak vibration peak at $2920 \mathrm{~cm}^{-1}$. The $\mathrm{O}-\mathrm{H}$ stretching vibration peak and $\mathrm{C}-\mathrm{H}$ stretching vibration peak were characteristic absorption peaks of polysaccharide. These peaks revealed that the crude polysaccharide components from $A$. hybridus were carbohydrates.

The asymmetric stretching absorption peak at $1638 \mathrm{~cm}^{-1}$ was attributed to $\mathrm{C}=\mathrm{O}$, and the stretching vibration peak at $1413-1550 \mathrm{~cm}^{-1}$ was attributed to $\mathrm{N}-\mathrm{H}$. The two peaks were characteristic absorption peaks of protein, indicating that the sample components contained proteins. The three chemistry components of crude polysaccharide also indicated that the sample contained some protein. The peaks at $1326 \mathrm{~cm}^{-1}$ and $1242 \mathrm{~cm}^{-1}$ were possibly due to the stretching vibration of $\mathrm{O}-\mathrm{H}$. The peaks at $1076 \mathrm{~cm}^{-1}$ and $1023 \mathrm{~cm}^{-1}$ were preliminarily assigned to the stretching vibration of $\mathrm{C}-\mathrm{O}$; these peaks were possibly due to $\mathrm{C}-\mathrm{O}-\mathrm{C}$ glycosidic bonds and $\mathrm{C}-\mathrm{O}-\mathrm{H}$ glycosidic rings or may be due to $\mathrm{C}-\mathrm{O}-\mathrm{H}$ and $\mathrm{C}-\mathrm{O}-\mathrm{R}$ of GalA carboxyl groups 
227 (Kacurakova et al., 2000; Sun et al., 2005). The peak at $890 \mathrm{~cm}^{-1}$ was the characteristic

228 absorption peak of $\beta$-isomers of pyranose, and the peak at $840 \mathrm{~cm}^{-1}$ was the characteristic

229 absorption peak of C-H bond of a-isomers of pyranose. AHP-H had an obvious absorption peak

230 at $827 \mathrm{~cm}^{-1}$ and a weak absorption peak at $890 \mathrm{~cm}^{-1}$, indicating that the main component of AHP-

$231 \mathrm{H}$ was a-isomers of pyranose and contained a certain amount of $\beta$-isomers of pyranose.

2323.3 UVS analysis of crude polysaccharide

233 The UVS (Mao et al., 2006) of crude polysaccharide from A. hybridus is shown in Fig. 2. It is

234 known that crude polysaccharide has absorption peaks at $206 \mathrm{~nm}$. The larger absorption peak

235 was between $250 \mathrm{~nm}$ and $300 \mathrm{~nm}$, indicating that the crude polysaccharide contained proteins

236 and nucleic acid, which is consistent with the FT-IR and of chemistry constitution results. There

237 was no absorption at $620 \mathrm{~nm}$, suggesting the pigment was completely eliminated.

$238 \quad 3.4$ SEM analysis

The effect on the polysaccharide surface structure is shown in Fig. 3. The hot water method had little effect on the surface structure of polysaccharide since the structure surface was smooth and dense. Compared with hot water method, the surface structure of polysaccharides was

242 affected by microwave-assisted extraction. The surface of polysaccharides extracted by 243 microwave-assisted was uneven and some bubbles appeared. Microwave heating made the 244 polysaccharide heated first from inside to outside, resulting in uneven heat transfer, and the 245 difference of temperature between inside and outside, which resulted in the appearance of 
246 bubbles or folds on the surface structure of polysaccharides. It also proved that microwave

247 heating destroyed the surface structure of polysaccharides to a certain extent. These results

248 suggested that the hot water method was gentler than the microwave-assisted extraction, and it

249 was less harmful to the polysaccharide surface structure and was a gentle method of

250 polysaccharide extraction. The structure and function of the substances were adaptable, so it can

251 be inferred that the dense or loose surface structure of the crude polysaccharide of Amaranthus

252 was related to its antioxidant activity. Some experimental results show that glucuronic acid is an

253 effective index of antioxidant activity of polysaccharides, which may be attributed to the

254 presence of electrophilic groups such as aldehydes or ketones in polysaccharides, it can promote

255 the release of hydrogen atoms of $\mathrm{O}-\mathrm{H}$ bond. Polysaccharide conjugates with high content of

256 glucuronic acid have stronger scavenging effect on reactive oxygen species, indicating that the

257 content of glucuronic acid has direct influence on the antioxidant activity of polysaccharides.

258 The dense surface structure was conducive to protecting its uronyl or alcohol hydroxyl groups

259 from being destroyed in extraction, and thus was conducive to its antioxidant activity.

260

3.5 Preliminary purification of polysaccharides from $A$. hybridus

DEAE cellulose-32 column chromatography was used to purify crude polysaccharides from

$263 \mathrm{~mol} / \mathrm{L}, 0.3 \mathrm{~mol} / \mathrm{L}, 0.5 \mathrm{~mol} / \mathrm{L}$ and $0.8 \mathrm{~mol} / \mathrm{L}$. The elution curve is shown in Fig. 4. The elution

264 curves of polysaccharides have four peak values, but the $\mathrm{ddH}_{2} \mathrm{O}$ from tubes 1 to 50 do not have

265 peaks, indicating that the polysaccharide solution contains acidic polysaccharide instead of 
266 neutral polysaccharide.

267 The elution peak of the polysaccharide presented at $0.1 \mathrm{~mol} / \mathrm{L} \mathrm{NaCl}$, and when eluted with 0.5

$268 \mathrm{~mol} / \mathrm{L} \mathrm{NaCl}$, a higher elution peak appeared; yet, the other gradients did not have peaks or their

269 peak values were smaller. Therefore the elution components from $0.1 \mathrm{~mol} / \mathrm{L} \mathrm{NaCl}$ and $0.5 \mathrm{~mol} / \mathrm{L}$

$270 \mathrm{NaCl}$ were named AHP-H-1 and AHP-H-2, respectively. The collected components were

271 desalted and dried to obtain the two pure polysaccharide samples.

272 3.6 Chemical compositions of the purified polysaccharide

The purified polysaccharide contents of the neutral polysaccharides, uronic acid and protein are shown in Table 2. The polysaccharides of A. hybridus were acidic polysaccharides. After purification, the contents of the neutral polysaccharides and uronic acid increased and protein content was significantly reduced, which indicated that most of the proteins were removed from

277 the polysaccharide. 
285 which indicated there were conjugates of polysaccharides from A. hybridus that might be

286 difficult to separate.

2873.8 Molecular weight of purified polysaccharides and analysis of the monosaccharide 288 composition

289 The relative molecular mass of the polysaccharides was measured with Dextran G-100. 290 Drawing a standard curve and taking Ve was taken as the ordinate and $\lg (\mathrm{Mr})$ as the abscissa, the 291 calculation formula of the molecular weight standard curve was as follows: $\mathrm{Ve}=-24.763 \lg (\mathrm{Mr})$ $292+158.09, \mathrm{R}^{2}=0.9913$; the formula had a good linear relationship and reliability. The result is 293 shown in Fig. 6.

294 For determining the elution volume, the two purified polysaccharides AHP-H-1 and AHP-H-2, 295 were eluted according to the standard curve method. The molecular weight is shown in Table 3. 296 The molecular weight of the polysaccharides from A. hybridus were $70.795 \mathrm{kDa}$ and 90.3325 $297 \mathrm{kDa}$, respectively.

298 Components analysis of purified polysaccharides from A. hybridus was carried out through 299 GC-MS, and the results are shown in Fig.7 and Table 4. There were significant differences 300 between the two polysaccharides. AHP-H-1 consisted of seven monosaccharide components 301 which include mannose, rhamnose, galactose, lyxose, xylose, fructose and glucose. AHP-H-1 did 302 not include xylose and fructose, and the content of glucose was much higher than that of the 303 other monosaccharide components. Its glucose content was $33.43 \%$. 
304

305

306

307

308

309

310

311

312

313

314

315

316

317

318

319

320

321

3.9 Antioxidant activity of the purified polysaccharides

3.9.1 DPPH radical scavenging activity

The results of the DPPH radical scavenging activity analysis are shown in Fig. 8. All samples had a high DPPH free radical scavenging activity. The free radical scavenging rate of the two polysaccharides basically showed a linear relationship in the range of $0-1 \mathrm{mg} / \mathrm{mL}$. When the concentration reached $2 \mathrm{mg} / \mathrm{mL}$, AHP-H-2 had the highest DPPH radical scavenging activity, the scavenging rate was above $80 \%$ and the scavenging rate of $\mathrm{AHP}-\mathrm{H}-1$ was close to $80 \%$. The $\mathrm{IC}_{50}$ of each component was as follows: AHP-H-1 was $0.908 \mathrm{mg} / \mathrm{mL}$ and AHP-H-2 was $0.595 \mathrm{mg} / \mathrm{mL}$.

\subsubsection{Scavenging activity of the hydroxyl radical}

The hydroxyl radical is a type of powerful free radical. The scavenging effect of purified polysaccharide from $A$. hybridus was very weak. When the concentration of the polysaccharide solution was at $2 \mathrm{mg} / \mathrm{mL}$, its scavenging rate was still within 40\%. AHP-H-2 had the highest hydroxyl radical scavenging rate at $48.5 \%$. Therefore, polysaccharides from $A$. hybridus were not suitable as powerful antioxidants. The minimum $\mathrm{IC}_{50}$ of $\mathrm{AHP}-\mathrm{H}-2$ was $2.123 \mathrm{mg} / \mathrm{mL}$. The results are shown in Fig. 9.

3.9.3 Scavenging activity of the superoxide anion free radical

The purified polysaccharides from $A$. hybridus had a higher scavenging ability than the superoxide anion free radical and had a higher superoxide anion free radical scavenging activity. 
322 When the concentration of polysaccharide solution was $2 \mathrm{mg} / \mathrm{mL}$, the scavenging rate of the

323 superoxide anion radical in solution was more than $60 \%$. AHP-H-2 had the highest superoxide

324 anion radical scavenging rate, close to $80 \%$, and its minimum $\mathrm{IC}_{50}$ was $0.999 \mathrm{mg} / \mathrm{mL}$.

325 Superoxide anion radicals mainly destroy organisms' macromolecules, so polysaccharides from

326 A. hybridus can be exploited as mild and durable antioxidants. The results are shown in Fig. 10.

$327 \quad 3.9 .4 \mathrm{Fe}^{3+}$ reducing capacity results

328 The reducing capacity of $\mathrm{Fe}^{3+}$ is a measure of its oxido-reduction capacity. The reducing

329 power of the purified polysaccharide is shown in Fig. 11. The two types of polysaccharides had a

330 certain reducing power that was dependent on their concentration. When the concentration was 2

$331 \mathrm{mg} / \mathrm{mL}$, the reducing power of the solution reached its maximum. The strongest reducing powers

332 of AHP-H-1 and AHP-H-2 were 0.695 and 0.918 , respectively.

$333 \quad$ 3.9.5 Total free radical scavenging activity

The T-AOC total antioxidant activity kit was used for investigating the total free radical scavenging activity of the two purified polysaccharides. The total antioxidant capacity per milligram of AHP-H-1 was 2.2 and the total antioxidant capacity per milligram of AHP-H-2 was 6.5. Vc was used as the control, and its total antioxidant capacity per milligram of Ve was 4.5. The total antioxidant capacity of AHP-H-2 was higher than that of Vc, which indicated that the total antioxidant capacity of the polysaccharide with a higher uronic acid content was stronger.

\section{DISCUSSION}


341 Plant polysaccharides are divided into intracellular polysaccharides, extracellular

342 polysaccharides and cell wall polysaccharides (Zhang, 2007). There are differences in the

343 cytoderm of different plants, so there are differences in the extraction conditions from diverse

344 plants, and the extraction conditions of polysaccharides from all kinds of tissues of the same

345 plant are also different, and therefore, the conditions for extracting polysaccharides are different.

346 In this study, polysaccharides from $A$. hybridus were extracted by a hot water method, and when

347 the temperature was lower than $92^{\circ} \mathrm{C}$, the ratio of material to liquid was less than $1: 43 \mathrm{mg} / \mathrm{mL}$

348 and the extraction time was less than $214 \mathrm{~min}$, and the extraction rate of polysaccharide

349 increased with the increase in extraction conditions. However, when the extraction conditions

350 were exceeded, the result was the opposite, similar to Shen Shian (Shen, 2014) for Paris

351 polyphylla extraction. When the temperature exceeded a certain value, the extraction percent of

352 the polysaccharide decreased with any increasement of temperature, and it is possible that the

353 high temperature causes the dissolution of impurities in the material, which increases the

354 concentration of the solution and reduces the dissolution percent of the polysaccharide, thus

355 affecting the yield of the polysaccharide. SEM observations of the polysaccharides showed that

356 the polysaccharide structure extracted by the hot water method was intact and was not damaged.

357 It was reported that the amaranth seeds contain $15 \%-19 \%$ of proteins with a higher proportion

358 of essential amino acids such as lysine, methionine, and tryptophane, $65 \%-75 \%$ of starch, $5 \%-7 \%$

359 of lipids, and 3\%-4\% of minerals. They have 2-3 times higher content of saccharose in

360 comparison to wheat grain. For the neutral sugars, determined after acid hydrolysis of the sample, 
361 glucose is the predominating component, which is in accord with the high starch content of

362 amaranth flours ranging between 62-69\%. However, a part of glucose originates from cell wall

363 polysaccharides, i.e. cellulose and hexoglycan-type hemicelluloses. Another part together with

364 some mannose was formed during the hydrolysis and reduction steps from the reported

365 saccharose component of amaranth flour. Only about $7 \%$ of the neutral sugars accounts for

366 xylose, arabinose, and galactose, and presumably they present as hemicelluloses of the

367 arabinoxylan and arabinogalactan types, known to occur in grain of grasses and cereals

368 (Burisova et al., 2000). Compared with the Bamboo mentioned in the introduction, they all have

369 glucose, galactose and xylose, and glucose accounts for a large proportion.

370 The structural characteristics of polysaccharides affect their biological activities, such as

371 chemical composition, molecular weight, type and conformation of glycoside bonds. The in vitro

372 antioxidant activity, reduction ability and free radical scavenging activity of purified samples

373 showed that the antioxidant activity of $A$. hybridus polysaccharides in vitro had no obvious

374 correlation with their monosaccharide composition and proportion, but only with the alcohol

375 hydroxyl group or its chemical molecular structure. Some alcohol hydroxyl groups in

376 polysaccharides can react with metal ions and play an anti-oxidant role by inhibiting free radical

377 chain reactions (Qi, 2008). According to a large number of in vitro antioxidant studies,

378 polysaccharides do have certain antioxidant activities. However, the relationship between

379 antioxidant activity, physical and chemical properties or structural characteristics is not clear,

380 and the underlying mechanism is uncertain. In addition, by comparing a large number of 
381 literatures, the results of the conflict were found, because different sources and extraction

382 methods can affect the properties of polysaccharides. On the other hand, there is little

383 information about the antioxidant activity of high purity polysaccharides. Other antioxidants,

384 such as proteins and polyphenols, always exist in polysaccharides in the form of complexes or

385 mixtures. The research on these factors affecting the antioxidant activity of polysaccharides is

386 not very in-depth, nor systematic, which needs further in-depth study. With the deepening of

387 research, the study of antioxidant mechanism of polysaccharides in vitro will be paid more

388 attention.

389 The results of the experiments showed that the two polysaccharides had strong antioxidant

390 activity, but for hydroxyl free radicals, polysaccharides from $A$. hybridus had not shown good

391 elimination capacity, which illustrates that the polysaccharides are a type of mild radical

392 scavenging substance. This study paved the way for the development and application of

393 polysaccharide antioxidant products.

\section{Conclusions}

395 To conclude, the results of this study confirmed that the two polysaccharides purified from $A$.

hybridus have strong antioxidant activity, including DPPH radical scavenging activity and

397 superoxide anion free radical scavenging activity. Compared with other antioxidant abilities, the polysaccharides of $A$. hybridus have weaker scavenging ability to hydroxyl radicals. This study 
400 for its development.

\section{REFERENCES}

402 Sun HL. 1998. Recommend a foodstuffs and crops - grain amaranth. Contemporary Animal 403 Husbandry.

404 Zhu QW. 1990. Amaranth grain - a wonderful flower in the kingdom of feed crops. Scientific 405 Fish Farming.

406 Gu GG. 2004. Shen Nong's Herbal Classic. Collection edition: Lanzhou Univrsity Press.

407 Johns T, Eyzaguirre PB. 2007. Biofortification, biodiversity and diet: a search for 408 complementary applications against poverty and malnutrition. Food Policy 32:1-24.

409 Caselato-Sousa VM, Amaya-Farf' an J. 2012. State of knowledge on amaranth grain: a 410 comprehensive review. J Food Sci 77:R93-104.

411 Yang X, Wang R, Zhang S, Zhu W, Tang J, Liu J, Chen P, Zhang D, Ye W, Zheng Y. 2014. 412 Polysaccharides from Panax japonicus C.A. Meyer and their antioxidant activities. Carbohydrate 413 Polymers 101: 386. DOI:10.1016/j.carbpol.2013.09.038

414 Tahmouzi S, Ghodsi M. 2014. Optimum extraction of polysaccharides from motherwort leaf and 415 its antioxidant and antimicrobial activities. Carbohydrate Polymers 112: 396. DOI: $416 \quad 10.1016 /$ j.carbpol.2014.06.024 
417 Han X, Shen S, Liu T, Du X, Cao X, Feng H, Zeng X. 2015. Characterization and antioxidant

418 activities of the polysaccharides from Radix Cyathulae officinalis Kuan. International Journal of

419 Biological Macromolecules 72: 544-52. DOI:10.1016/j.ijbiomac.2014.09.007

420 Kim YS, Kang KS, Kim SI. 1990. Study on antitumor and immunomodulating activities of

421 polysaccharide fractions from Panax ginseng : Comparison of effects of neutral and acidic

422 polysaccharide fraction. Archives of Pharmacal Research 13: 330-337.

423 DOI:10.1007/bf02858168

424 Jin M, Huang Q, Zhao K, Shang P. 2013. Biological activities and potential health benefit effects

425 of polysaccharides isolated from Lycium barbarum L. International Journal of Biological

426 Macromolecules 54: 16-23. DOI:10.1016/j.ijbiomac.2012.11.023

427 Chen SJ, Liu YJ, Wang YY, Chen DD, Liu T, Gu ZL. 2013. Effect of Lycium Barbarum

428 polysaccharide on production performance and serum biochemical indexes in lactating rabbit.

429 Scientia Agricultura Sinica 46: 2168-2174. DOI:10.3864/j.issn.0578-1752.2013.10.023

430 Tang Z, Gao H, Wang S, Wen S, Song, Q. 2013. Hypolipidemic and antioxidant properties of a 431 polysaccharide fraction from Enteromorpha prolifera. International Journal of Biological 432 Macromolecules 58: 186. DOI:10.1016/j.ijbiomac.2013.03.048

433 Zhou X, Wang H, Wang B, Liang F, Ming Y, Jing L, Zhou L, Ding, C. 2016. Characterization 434 and antioxidant activities of polysaccharides from the leaves of Lilium lancifolium Thunb. 
435 International Journal of Biological $\quad$ Macromolecules.

436 DOI:10.1016/j.ijbiomac.2016.07.028

437 Liu CM., Fu GM, Tu ZC, Wan Y. 2002. Study on the function Lily - polysaccharides to lower

438 the blood glucose. Journal of Food Science 23: 113-114. DOI: 10.3321/j.issn:1002-

$439 \quad 6630.2002 .06 .029$

440 Liao K, Bian Z, Xie D, Qiang P. 2016. A selenium-modified ginseng polysaccharide promotes

441 the apoptosis in Human Promyelocytic Leukemia (HL-60) Cells via a mitochondrial-mediated

442 pathway. Biological Trace Element Research 177: 64-71. DOI:10.1007/s12011-016-0879-9

$443 \mathrm{Hu}$ SZ. 2016. Substance interactions' foundation on antioxidant activities in vitro of complex

444 carbohydrates. Thesis, Nanchang University.

445 Li HY. 2009. Study of salt resistance and coupling effects of salt and fertilizer on amaranth .

446 Thesis, Nanjing Agricultural University.

447 Li XL, Wei GD, Wang ZJ, Chen PQ, Cai EN. 2006. Isolation, purification, character research of 448 polysaccharide from the stalk of Brassica juncea. Journal of Fujian Normal University(Natural 449 Science Edition) 22: 72-75. DOI:10.3969/j.issn.1000-5277.2006.02.017

450 Cuesta G, Suarez N, Bessio MI, Ferreira F, Massaldi H. 2003. Quantitative determination of

451 pneumococcal capsular polysaccharide serotype 14 using a modification of phenol-sulfuric acid 452 method. Journal of Microbiological Methods 52: 69-73. DOI:10.1016/s0167-7012(02)00151-3 
453 Albalasmeh AA, Berhe AA, Ghezzehei TA. 2013. A new method for rapid determination of 454 carbohydrate and total carbon concentrations using UV spectrophotometry. Carbohydrate 455 Polymers 97: 253-261. DOI:10.1016/j.carbpol.2013.04.072

456 Yang J, Wu ZT. 1998. Studies on optimum conditions for measurement of protein content by 457 Bradford method. Journal of sichuan Teachers College(Natural Science) 198-200. DOI: $458 \quad$ 10.16246/j.issn.1673-5072.1998.02.014

459 Fang DJ, Zhao RQ, Zhang XJ. 2011. Determination of total carbohydrate and uronic acid 460 contents in polysaccharides from Poria Cocos. Information on Traditional Chinese Medicine 28:

461 42-44. DOI: 10.3969/j.issn.1002-2406.2011.04.020

462 Zhang P, Li XM, Wang JN, Li X, Wang BG. 2015. New butenolide derivatives from the marine463 derived fungus Paecilomyces variotii with DPPH radical scavenging activity. Phytochemistry 464 Letters 11: 85-88. DOI:10.1016/j.phytol.2014.11.014

465 Beauchamp C, Fridovich I. 1971. Superoxide dismutase: improved assays and an assay 466 applicable to acrylamide gels. Analytical Biochemistry 44: 276-287. DOI:10.1016/0003$4672697(71) 90370-8$

468 Jia Z, Tang M, Wu J. 1999. The determination of flavonoid contents in mulberry and their 469 scavenging effects on superoxide radicals. Food Chemistry 64: 555-559. DOI:10.1016/s0308$470 \quad 8146(98) 00102-2$ 
$471 \mathrm{Hu}$ M. 2010. Shape-controlled synthesis of iron oxides and Prussian Blue analogues and the 472 study on nonclassical aystallization mechanism. Thesis, East China Normal University.

473 Sun Y. 2010. Extraction, purification, structure and antioxidant activities of polyphenols and 474 polysaccharides in Ilex Kudingcha. Thesis, Nanjing Agricultural Univesity.

475 Sun X. 2013. Preparation and characteristics of bioactive peptides from hydrolyzing extruded 476 corn protein meal. Thesis, DongBei Agricultural University.

477 Kacurakova M, Capek P, Sasinkova V, Wellner N, Ebringerova A. 2000. FT-IR study of plant 478 cell wall model compounds: pectic polyasaccharides and hemicelluloses. Carbohydrate Polymers 43: 195-203. DOI:10.1016/s0144-8617(00)00151-x

480 Sun Y, Tang J, Gu X, Li D. 2005. Water-soluble polysaccharides from Angelica sinensis (Oliv.) 481 Diels: Preparation, characterization and bioactivity. International Journal of Biological 482 Macromolecules 36: 283-289. DOI:10.1016/j.ijbiomac.2005.07.005

483

484

485

486 487

Mao WL, Xia XF, Tian LQ, Chen HS, Xu LY. 2006. Study on Poria Cocos herbs by ultraviolet spectrum group method. Journal of Hubei College of TCM 8: 37-38. DOI:10.3969/j.issn.1008987X.2006.01.014

Zhang SM. 2007. Isolation, purification and function study of Pueraria xyloglucan . Thesis, China Agricultural University. 
488 Shen S, Chen D, Li X, Li T, Yuan M, Zhou Y, Ding, C. 2014. Optimization of extraction process

489 and antioxidant activity of polysaccharides from leaves of Paris polyphylla. Carbohydrate

490 Polymers 104: 80. DOI:10.1016/j.carbpol.2014.01.006

491 Burisova A, Tomaskova B, Sasinkova V, Ebringerova A. 2001. Isolation and characterization of

492 the non-starch polysaccharides of amaranth seeds. Chem. Pap. 55: 254-260.

493 Qi L. 2008. Effects and mechanisms of flavonoids of Astragalus Complanatus against injuries 494 induced by radition. Thesis, Suzhou University.

495 Chen J. 2015. Screening and isolation of marine bacteria secreted exopolysaccharide, 496 optimization of fermentation conditions and the research on the immune activity of the 497 polysaccharide. Thesis, Guangxi University for Nationalities. 
Figure 1

FT-IR spectra of polysaccharide AHP-H.

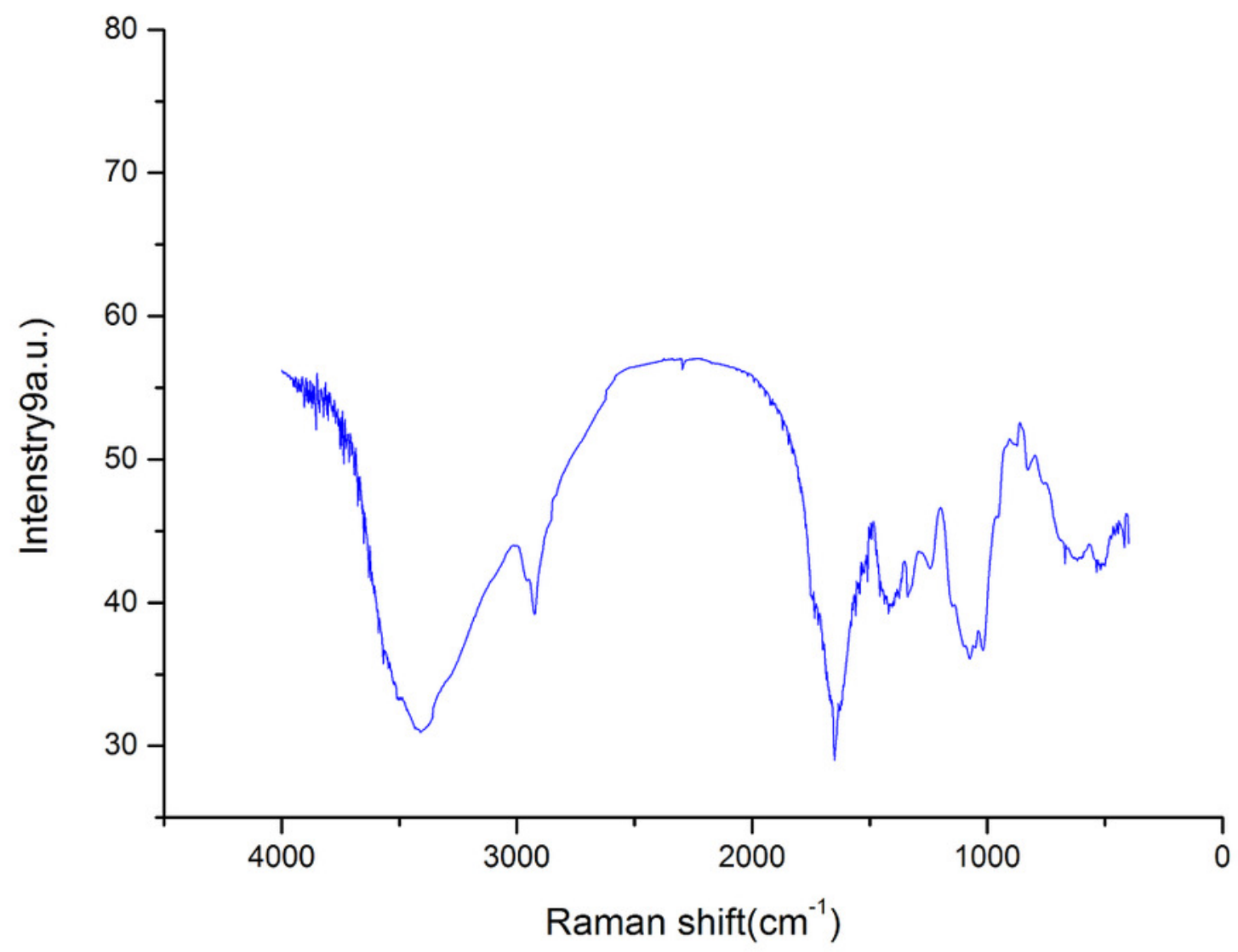


Figure 2

UVS absorption spectra of AHP-H.

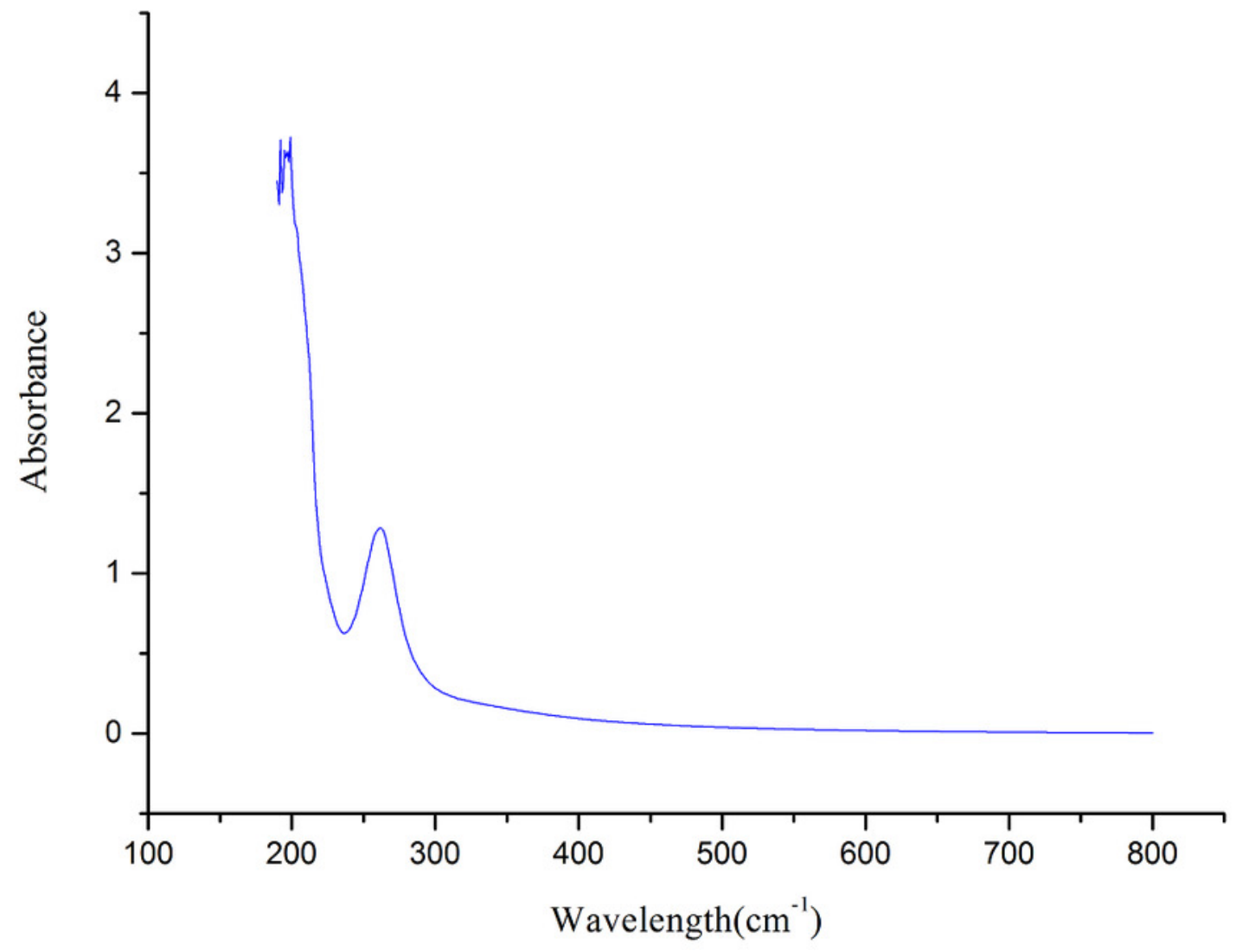




\section{Figure 3}

The figure of Scanning electron micrograhps of crude polysaccharide extracted by hotwater method and microwave-assist, A: AHP-H (1000x); B: AHP-H (3000x). C: AHP$M(1000 \times) ; D:$ AHP-M(3000x)

*Note: Auto Gamma Correction was used for the image. This only affects the reviewing manuscript. See original source image if needed for review.
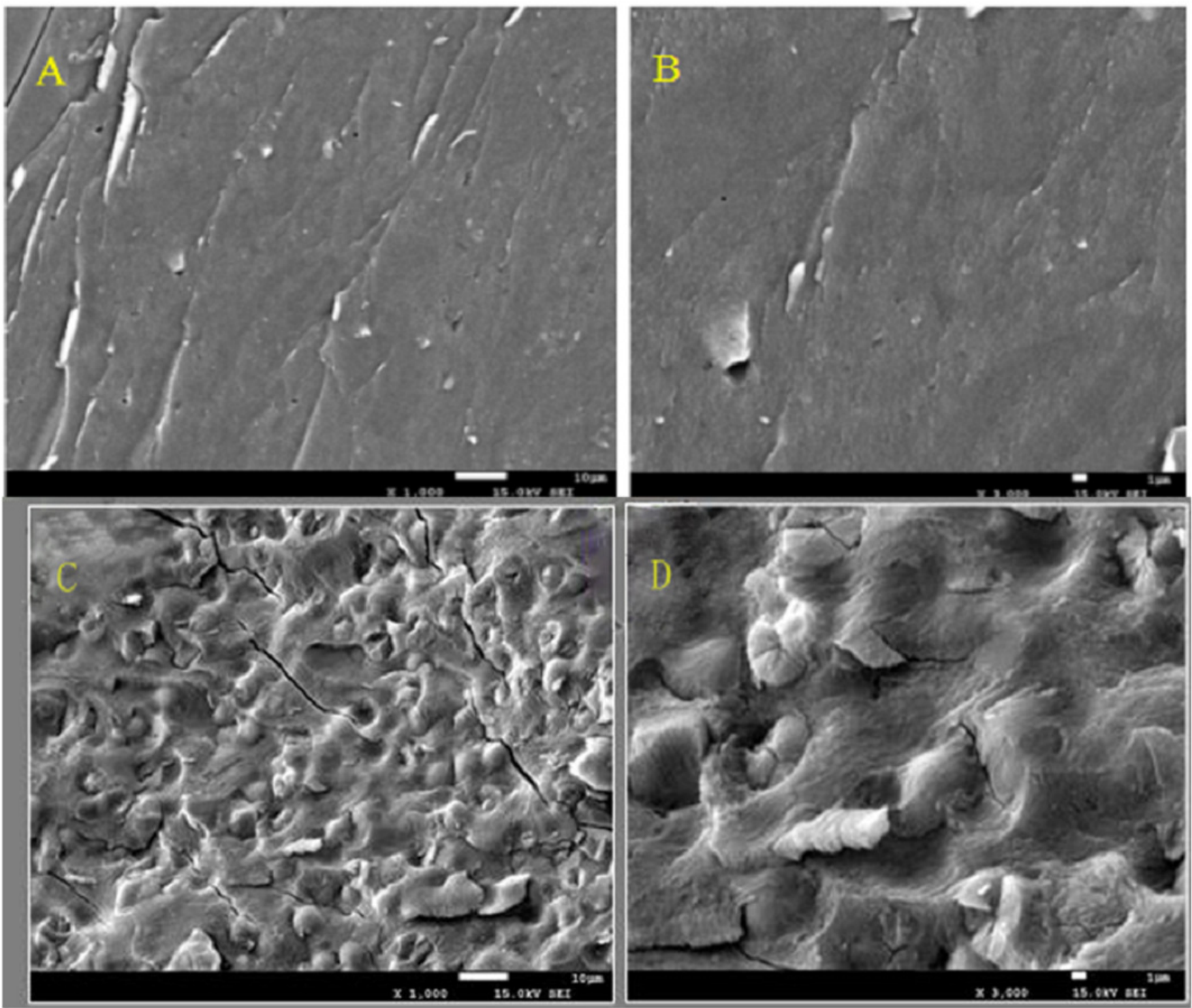
Figure 4

The figure of DEAE cellulose-32 column chromatogram of polysaccharide, AHP-H.

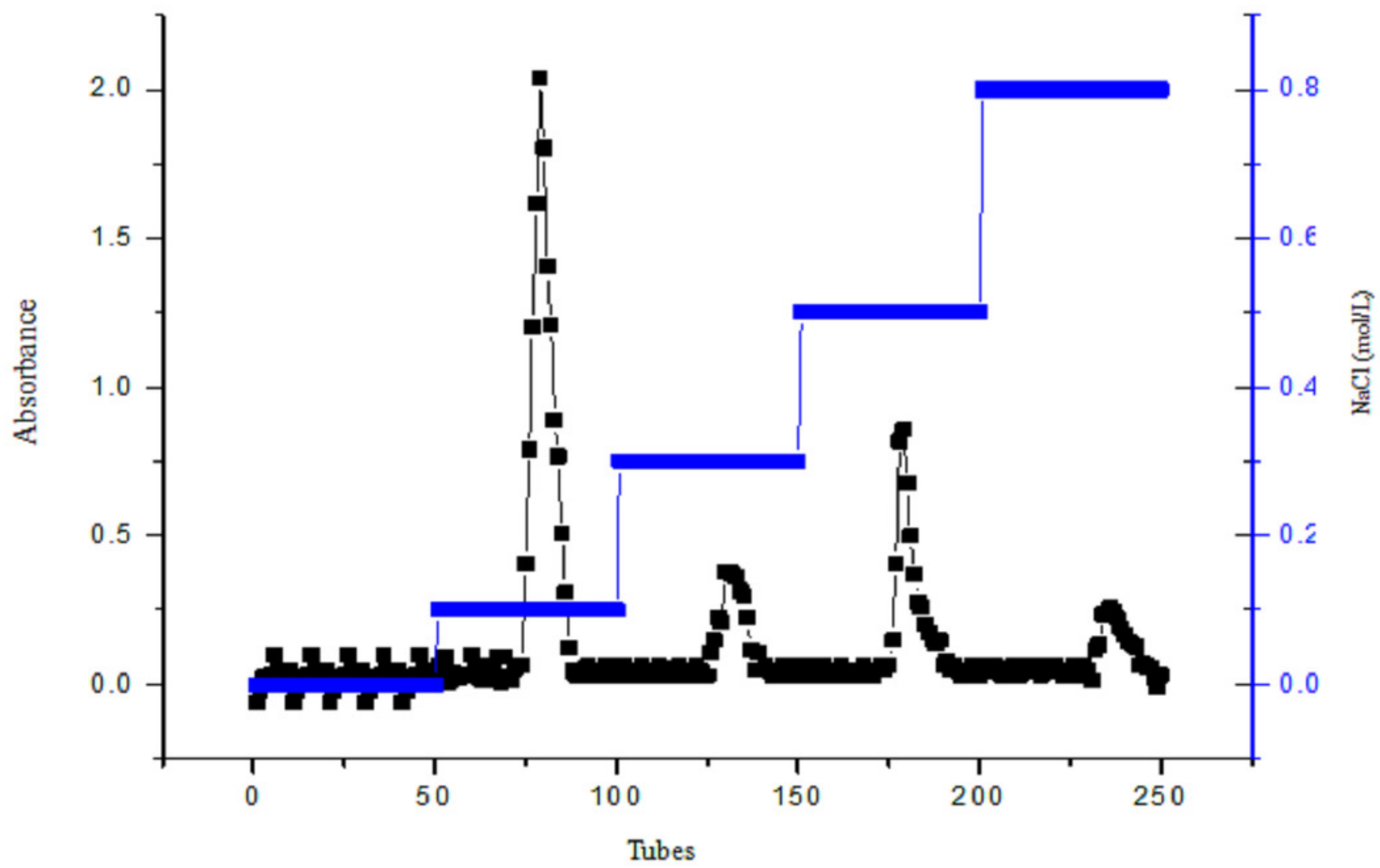


Figure 5

The FT-IR and UVS analysis of AHP-H-1 and AHP-H-2. A. FT-IR analysis of AHP-1 and AHP-2, B. UVS analysis of AHP-1 and AHP-2
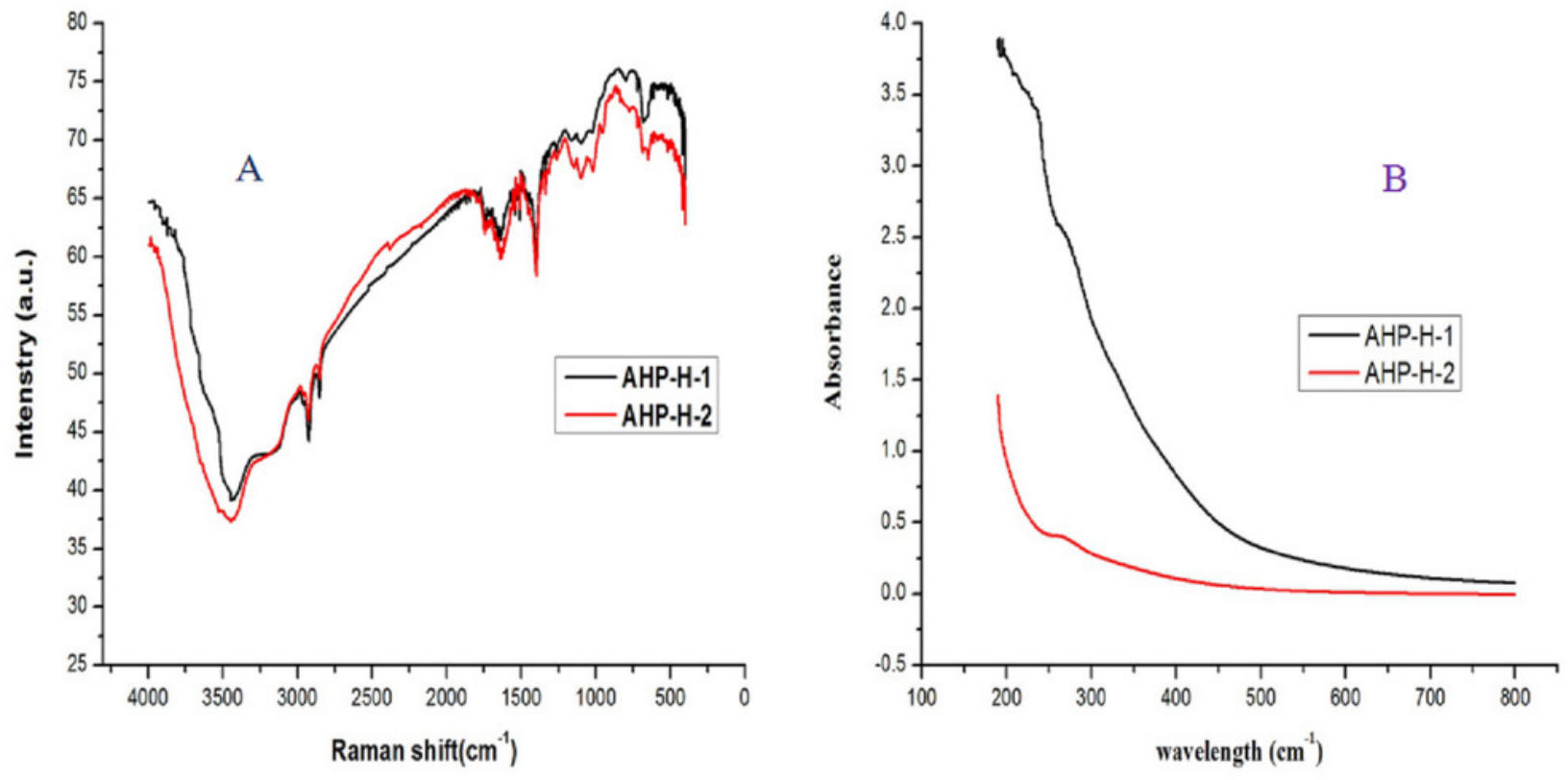
Figure 6

The figure of standard curve of the relative molecular weight.

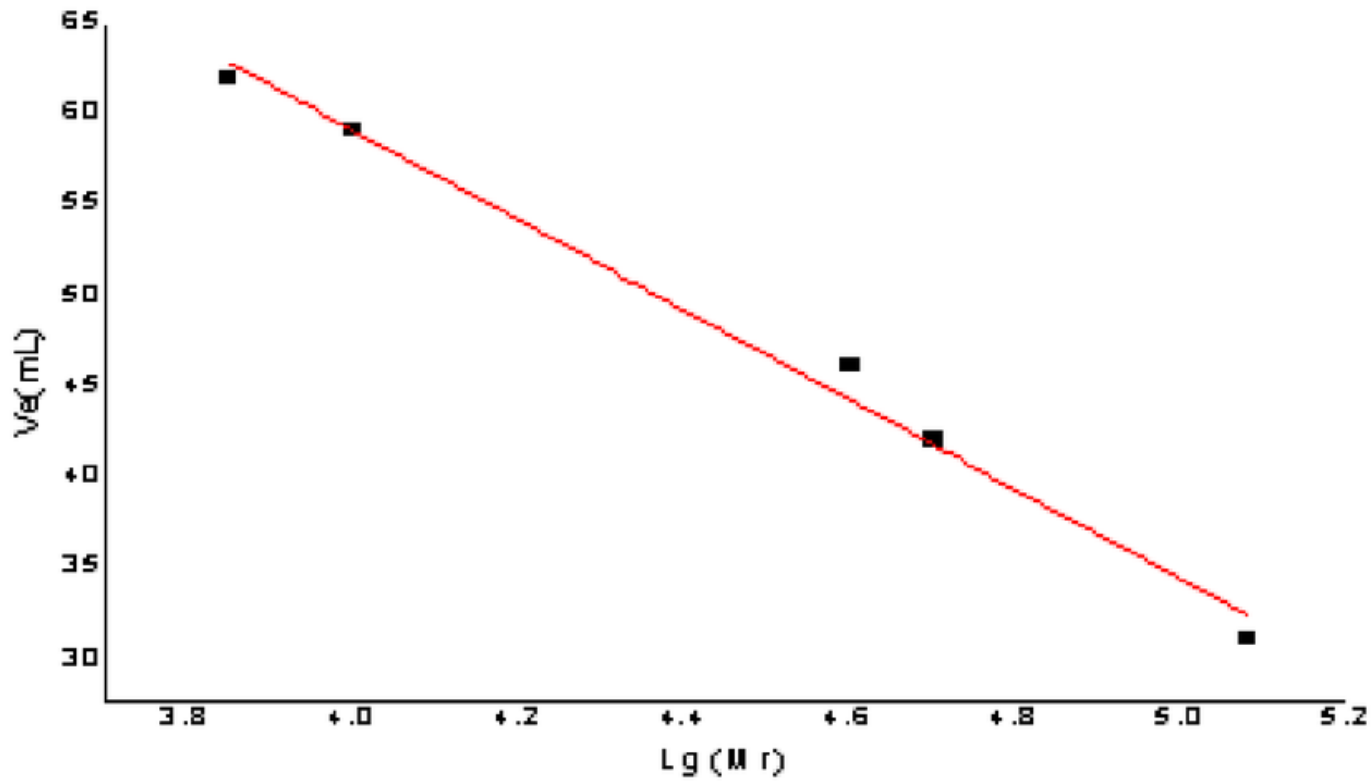


Figure 7

The GC-MS spectrometry of purified polysaccharides of AHP-H-1 (A) and AHP-H-2 (B).
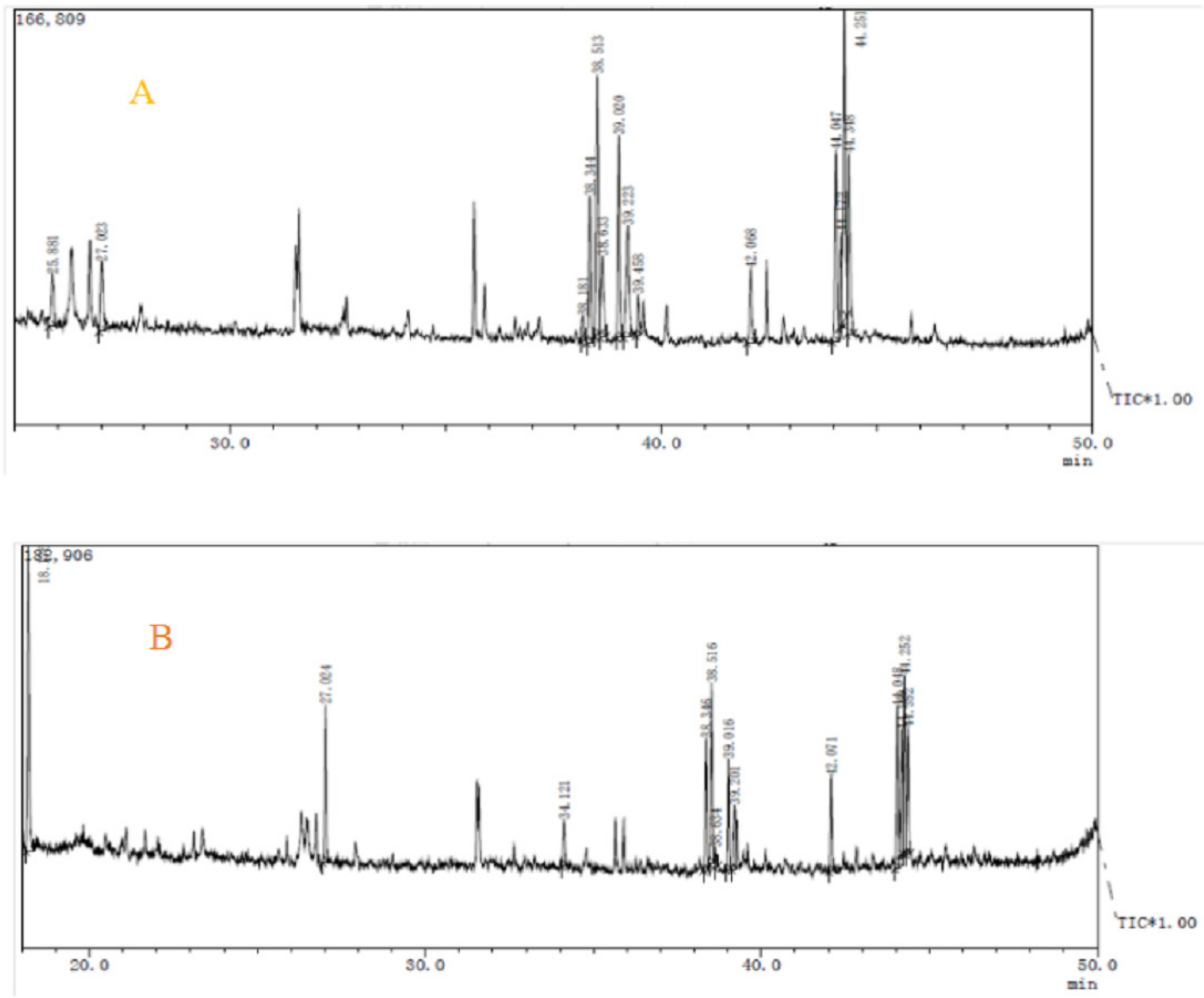
Figure 8

DPPH radical scavenging ability of purified polysaccharide.

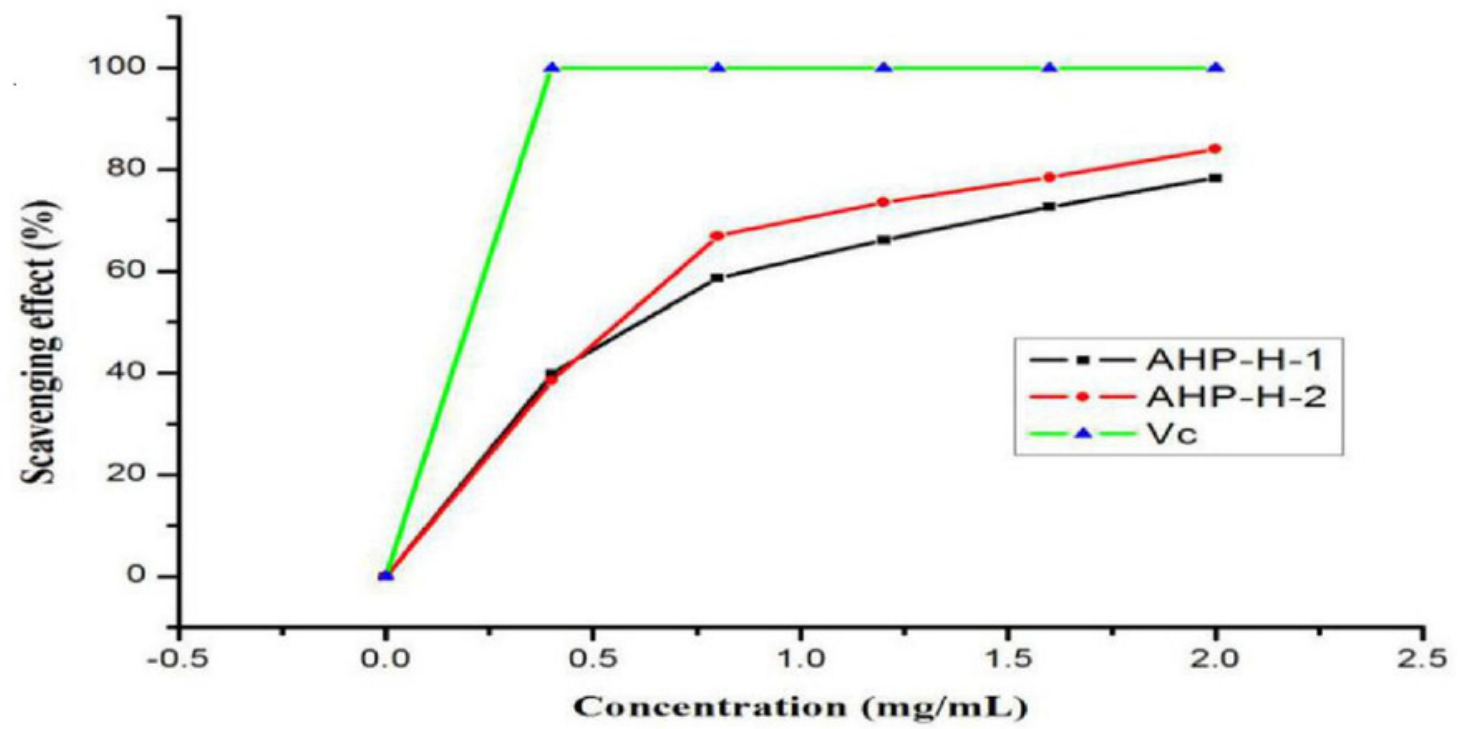


Figure 9

Hydroxyl radical scavenging ability of purified polysaccharide.

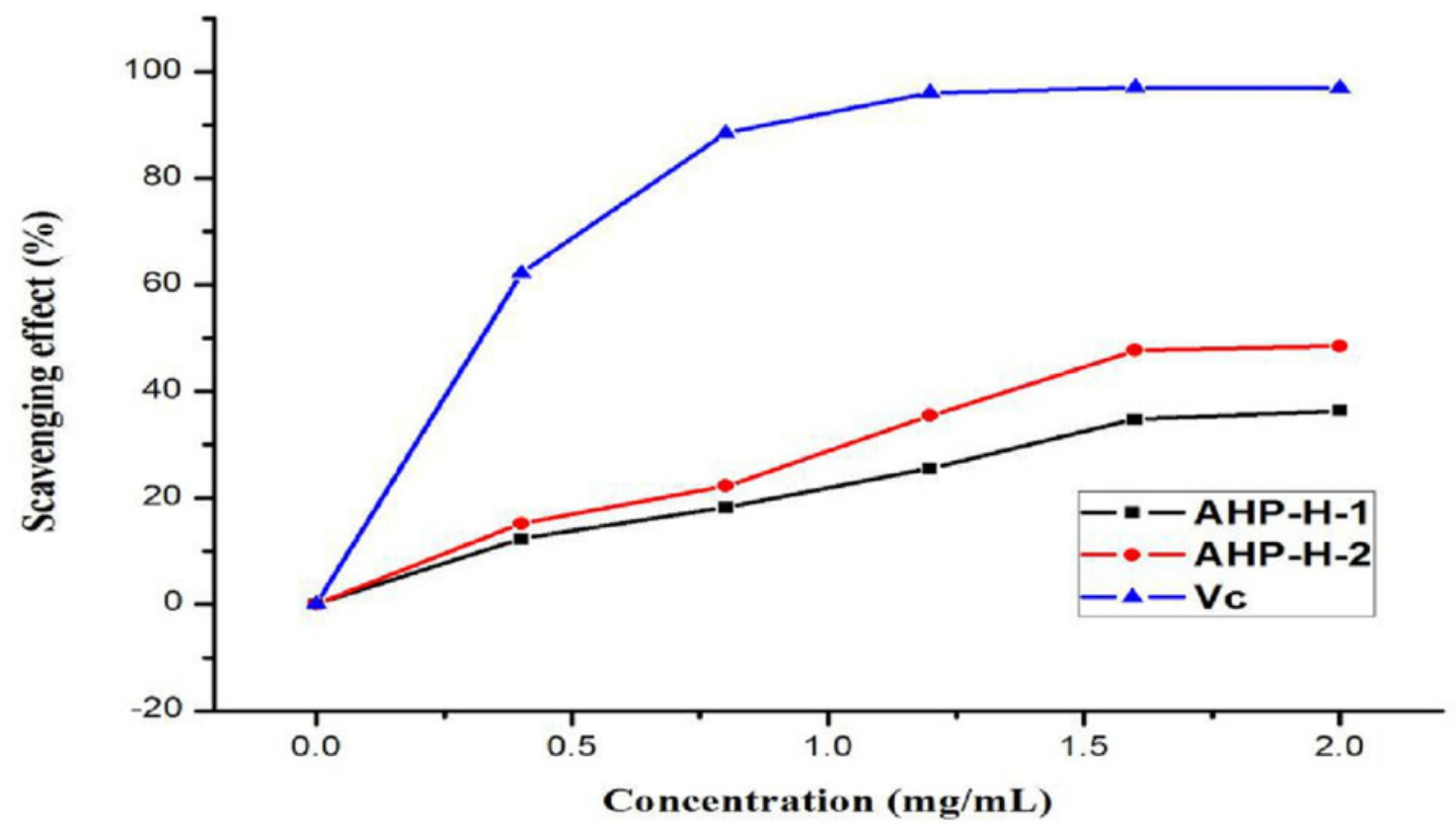


Figure 10

The superoxide anion free radical scavenging ability of purified polysaccharide.

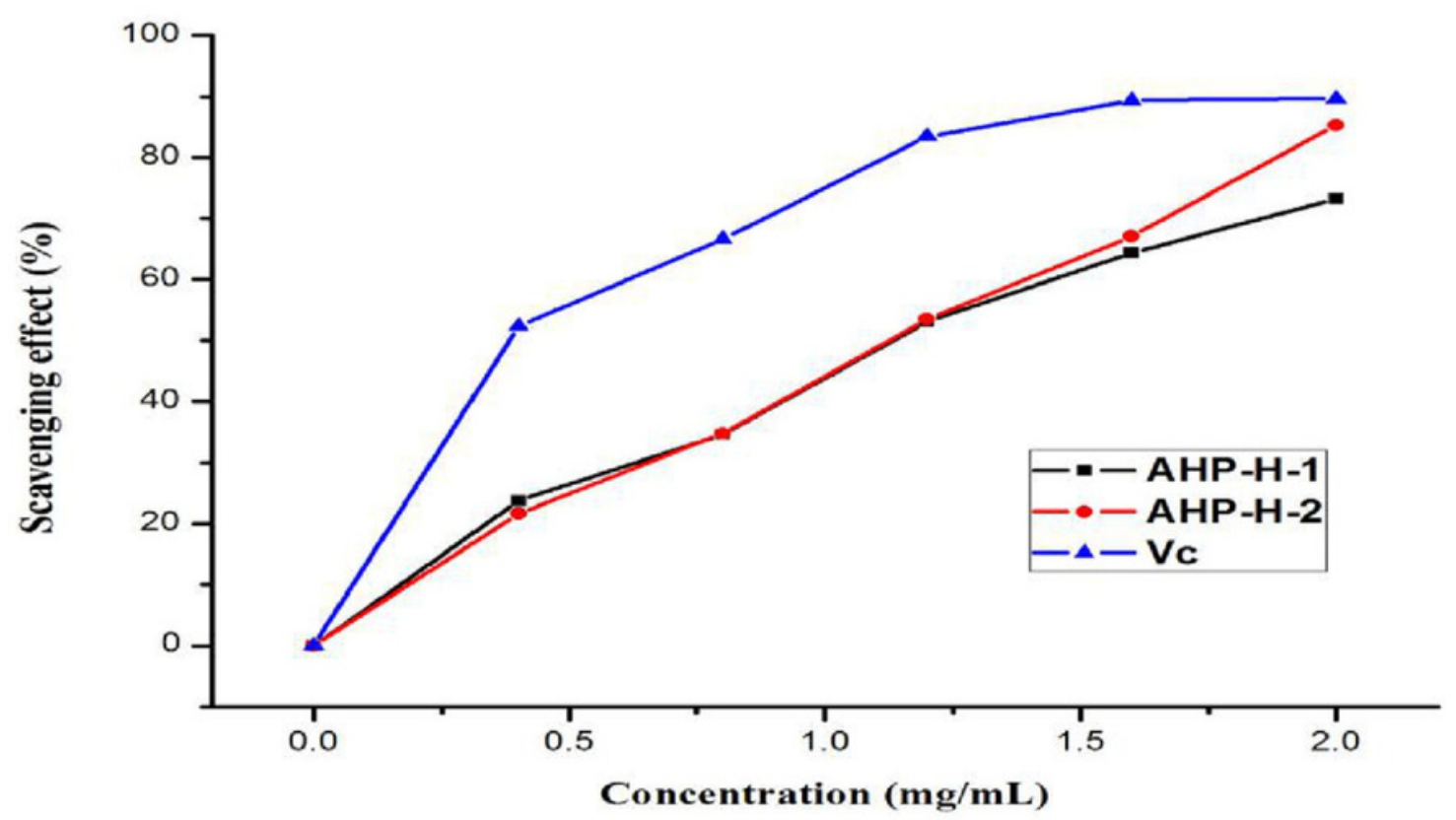


Figure 11

The reducing power of purified polysaccharide.

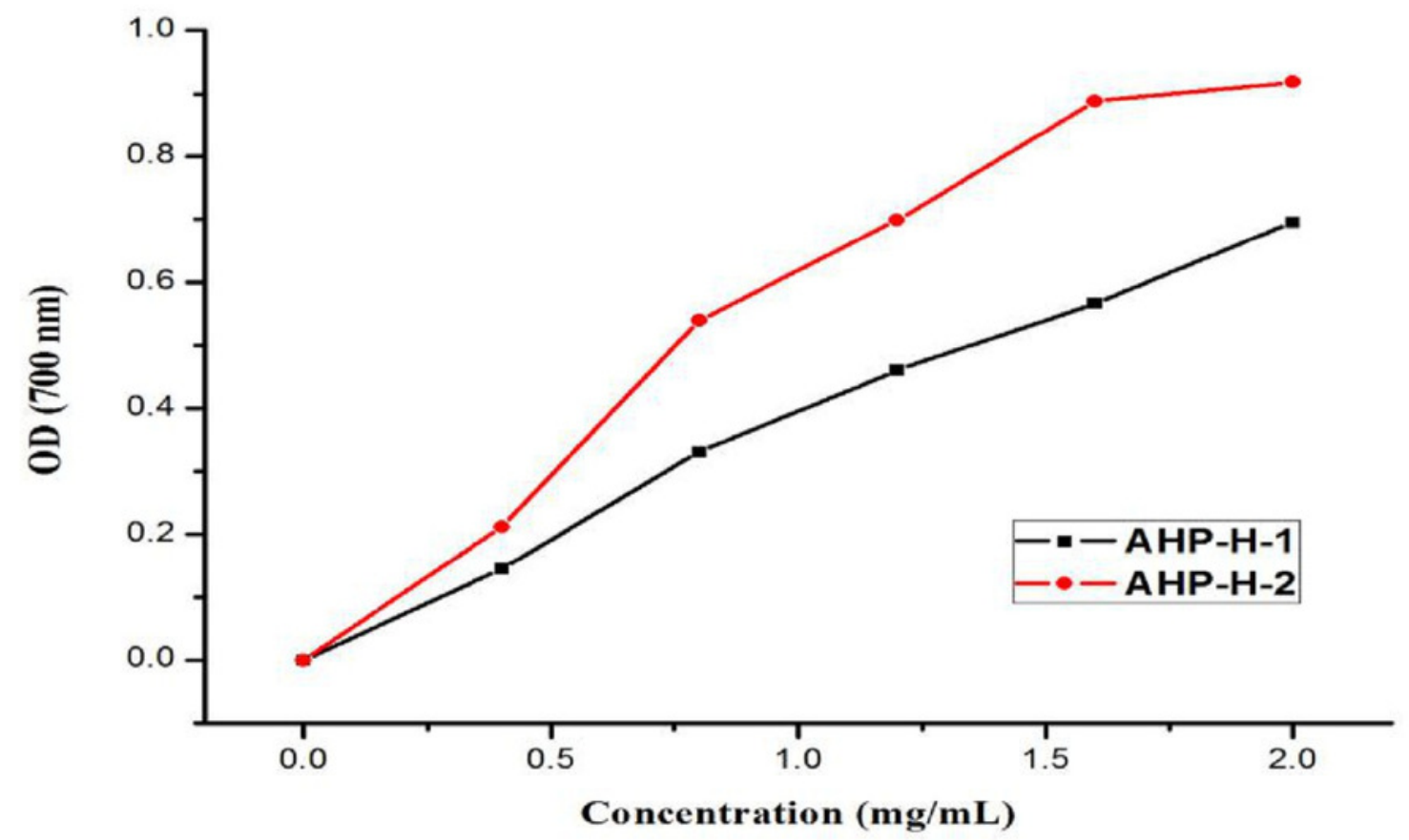




\section{Table $\mathbf{1}$ (on next page)}

The content of neutral sugar, uronic acid and protein in the crude polysaccharide, respectively. 
1

\begin{tabular}{llll}
\hline $\begin{array}{l}\text { Polysaccharide } \\
\text { sample }\end{array}$ & The content of & The content of & The content of \\
& polysaccharide & uronic acid (\%) & protein (\%) \\
& & & \\
\hline AHP-H & $35.4 \pm 0.93$ & $28.13 \pm 0.35$ & $3.14 \pm 0.25$ \\
\hline
\end{tabular}


Table 2 (on next page)

The content of polysaccharide, uronic acid and protein in the purified polysaccharide, respectively(\%). 


\begin{tabular}{llll}
\hline $\begin{array}{l}\text { Polysacchari- } \\
\text { de sample }\end{array}$ & $\begin{array}{l}\text { Neutral } \\
\text { polysaccharide } \\
\text { content(\%) }\end{array}$ & $\begin{array}{l}\text { Uronic-acid } \\
\text { content(\%) }\end{array}$ & Protein content(\%) \\
\hline AHP-H-1 & $55.6 \pm 0.78$ & $40.17 \pm 0.62$ & $0.24 \pm 0.04$ \\
AHP-H-2 & $45.7 \pm 0.56$ & $52.78 \pm 0.68$ & $0.42 \pm 0.12$ \\
\hline
\end{tabular}

1 
Table 3 (on next page)

The calculation table of molecular weight. 
1

\begin{tabular}{lll}
\hline $\begin{array}{l}\text { Polysaccharide } \\
\text { samples }\end{array}$ & AHP-H-1 & AHP-H-2 \\
\hline $\mathrm{Ve}(\mathrm{mL})$ & 38 & 35 \\
& \\
$\mathrm{Lg}(\mathrm{Mr})$ & 4.85 & 4.97 \\
$\mathrm{Mr}(\mathrm{Da})$ & 70,795 & 93,325 \\
\hline
\end{tabular}


Table 4 (on next page)

The monosaccharide composition(\%) of purified polysaccharide. 
1

\begin{tabular}{lll}
\hline Name & AHP-H-1 & AHP-H-2 \\
\hline Mannose & 22.2 & 20.41 \\
Rhamnose & 4.29 & 7.02 \\
Galactose & 28.5 & 19.72 \\
Lyxose & 12.99 & 19.34 \\
Xylose & 5.65 & nd \\
Fructose & 5.07 & nd \\
Glucose & 21.36 & 33.43 \\
\hline
\end{tabular}

